Widayat, D · U. Umiyati · Y. Sumekar

\title{
Campuran herbisida IPA glifosat, imazetafir, dan karfentrazon-etil dalam mengendalikan gulma daun lebar, gulma daun sempit, dan teki
}

Sari. Pengendalian gulma dengan menggunakan herbisida tunggal tidak dapat mengendalikan berbagai jenis gulma, oleh karena ituperlu dilakukan pencampuran herbisida. Campuran herbisida dengan dua atau lebih jenis bahan aktif dapat bersifat sinergis, aditif, atau antagonis. Tujuan penelitian adalah untuk mengetahui sifat campuran herbisida IPA glifosat, imazetafir, dan karfentrazon-etil terhadap gulma daun lebar, gulma daun sempit, dan teki. Penelitian dilakukan pada Oktober 2018 sampai Januari 2019 di Laboratorium Kultur Terkendali Universitas Padjadjaran, Jatinangor. Perlakuan terdiri dari empat jenis herbisida dengan enam dosis, yaitu herbisida campuran IPA glifosat $380 \mathrm{~g} / \mathrm{L}+$ imazetafir $40 \mathrm{~g} / \mathrm{L}+$ karfentrazon-etil $8 \mathrm{~g} / \mathrm{L}$ (dosis 2,000 L/ha; 1,000 L/ha; 0,500 L/ha; 0,250 L/ha; 0,125 L/ha, dan tanpa herbisida), dan herbisida tunggal masing-masing IPA glifosat 380 $\mathrm{g} / \mathrm{L}$, imazetafir $40 \mathrm{~g} / \mathrm{L}$, dan karfentrazon-etil $8 \mathrm{~g} / \mathrm{L}$ (dosis 3,000 L/ha; 1,500 L/ha; 0,750 L/ha; 0,375 L/ha; 0,188L/ha, dan tanpa herbisida), yang diulang empat kali. Gulma target terdiri dari Ageratum conyzoides, Borreria alata, Ischaemum timorense, Ottochloa nodosa, dan Cyperus rotundus. Data dianalisis dengan analisis regresi linier dan metode Multiplicative Survival Model untuk menentukan $\mathrm{LD}_{50}$ perlakuan dan $\mathrm{LD}_{50}$ harapan. Hasil penelitian menunjukan bahwa persentase kerusakan yang disebabkan oleh herbisida campuran IPA glifosat, imazetafir, dan karfentrazon-etil lebih tinggi daripada masing-masing herbisida secara tunggal. Sifat campuran herbisida IPA glifosat dengan imazetafir atau imazetafir dengan karfentrazon-etil memiliki nilai ko-toksisitas lebih dari satu $(>1)$ yang menunjukkan bahwa herbisida campuran bersifat sinergis pada gulma Ageratum conyzoides, Borreria alata, Ischaemum timorense, Ottochloa nodosa, dan Cyperus rotundus.

Kata kunci : Herbisida campuran · Imazetafir · IPA Glifosat · Karfentrazon-etil

\section{Herbicide mixture of IPA glyphosate, imazetaphyr, and Carfentrazone ethyl in controlling broad leaves weeds, grasses, and sedges}

\begin{abstract}
Weed control using a single herbicide cannot control various types of weeds, therefore it is necessary to mix herbicides. Herbicide mixtures with two or more types can be synergistic, additive, or antagonistic. The research objective was to determine the properties of the herbicide mixture IPA glyphosate, imazetafir, and karfentrazone-ethyl against broadleaves weeds, grasses, and sedges. The research was conducted from October 2018 to January 2019 at the Laboratory of Controlled Culture, Universitas Padjadjaran, Jatinangor. There were herbicide mixture of IPA glyphosate $380 \mathrm{~g} / \mathrm{L}+$ imazetaphyr $40 \mathrm{~g} / \mathrm{L}+$ carfentrazone-ethyl $8 \mathrm{~g} / \mathrm{L}$ (dose 2.000 L/ha, $1.000 \mathrm{~L} / \mathrm{ha}, 0.500 \mathrm{~L} / \mathrm{ha}, 0.250 \mathrm{~L} / \mathrm{ha}, 0.125 \mathrm{~L} / \mathrm{ha}$, and without herbicide), single herbicide IPA glyphosate $380 \mathrm{~g} / \mathrm{L}$, imazetaphyr $40 \mathrm{~g} / \mathrm{L}$, and carfentrazone-ethyl $8 \mathrm{~g} / \mathrm{L}$, respectively (dose $3.000 \mathrm{~L} / \mathrm{ha}, 1.500 \mathrm{~L} / \mathrm{ha}, 0.750 \mathrm{~L} / \mathrm{ha}, 0.375$ L/ha, $0.188 \mathrm{~L} / \mathrm{ha}$, and without herbicide), which was repeated four times. The target weeds consisted of Ageratum conyzoides, Borreria alata, Ischaemum timorense, Ottochloa nodosa, and Cyperus rotundus. Data were analyzed by linear regression and Multiplicative Survival Model to determine the $\mathrm{LD}_{50}$ treatment and $\mathrm{LD}_{50}$ expectations. The results showed that the percentage of damage caused by the herbicide mixture of IPA glyphosate, imazetaphyr, and carfentrazone-ethyl was higher than each herbicide. Mixture of IPA glyphosate with imazetaphyr or imazetaphyr with carfentrazone-ethyl had more than one $(>1)$ co-toxicity value which indicates that the mixed herbicide was synergistic in controlling of Ageratum conyzoides, Borreria alata, Ischaemum timorense, Ottochloa nodosa, and Cyperus rotundus.
\end{abstract}

Keywords : Carfentrazone-ethyl · Herbicide mixture · Imazetaphyr · IPA Glyphosate

Diterima : 25 Agustus 2020, Disetujui : 15 April 2021, Dipublikasikan : 16 April 2021 doi: https://doi.org/10.24198/kultivasi.v20i1.29236

Widayat, D · U. Umiyati · Y. Sumekar

Staff Pengajar Fakultas Pertanian Universitas Padjadjaran

Korespondensi: uum.umiyati@unpad.ac.id 


\section{Pendahuluan}

Gulma merupakan tumbuhan yang keberadaannya dapat mengganggu dalam proses budidaya pertanian baik pada tanaman hortikultura, pangan, ataupun perkebunan (Sembodo, 2010). Secara garis besar gulma merupakan salah satu faktor biotik yang menyaingi tanaman dalam perebutan cahaya, ruang tumbuh, serta penyerapan unsur hara dan air sehingga dapat menyebabkan penurunan hasil panen.

Pengendalian gulma selama ini terbatas pada penggunaan herbisida tunggal dengan satu jenis bahan aktif dan spesifik. Jenis herbisida selektif hanya mampu mengendalikan satu jenis gulma, dimana apabila salah satu gulma dikendalikan, maka gulma jenis lain yang lebih tahan akan menjadi dominan pada lahan, dan dapat menimbulkan masalah baru (Umiyati, 2005). Saat ini telah banyak dilaporkan adanya jenis-jenis gulma yang resisten terhadap herbisida sebagai akibat dari pengendalian gulma dengan menggunakan herbisida tunggal secara berulang-ulang. Sebanyak 352 biotipe gulma telah dilaporkan menjadi biotipe resisten (Weedscience, 2011). Penggunaan herbisida berbahan aktif sama secara berulang-ulang akan mematikan individu gulma yang rentan, tetapi meninggalkan individu yang resisten terhadap herbisida tersebut.

Perkembangan teknologi pencampuran herbisida dengan bahan aktif berbeda bertujuan untuk mendapatkan spektrum pengendalian yang lebih luas, serta diharapkan dapat memperlambat tumbuhnya gulma yang resisten terhadap herbisida, mengurangi biaya produksi, serta mengurangi residu herbisida. Salah satu hal yang harus dicermati dalam pencampuran herbisida adalah apakah campuran tersebut bersifat antagonistik atau tidak. Jika campuran herbisida tersebut bersifat antagonis, maka pengendalian gulma dengan herbisida campuran tersebut tidak akan efektif. Oleh karena itu, suatu campuran herbisida perlu diuji sifat aktivitasnya, dan ini ditentukan oleh jenis formulasi, cara kerja, dan jenis-jenis gulma yang dikendalikan (Guntoro dan Fitri, 2013).

Metode pencampuran herbisida tidak selalu menimbulkan gejala yang positif. Setiap bahan aktif yang terkandung dalam herbisida memiliki jenis formulasi, cara kerja, dan spesifikasi jenis gulma yang berbeda. Reaksi campuran dapat gejala positif (efek sinergis), yang berarti pencampuran herbisida dapat meningkatkan efisiensi penggunaan herbisida dalam mengendalikan gulma sasaran. Gejala negatif ditunjukkan dengan efek antagonis pada gulma sasaran, yakni berkurangnya daya mematikan gulma. Oleh karena itu, suatu campuran beberapa bahan aktif herbisida perlu diuji sifat aktivitasnya, untuk mengetahui adanya aktivitas antagonisme herbisida (Guntoro dan Fitri, 2013).

Tjitrosemito dan Burhan (1995) mengungkapkan bahwa interaksi bahan aktif akibat pencampuran dua atau lebih herbisida dapat menimbulkan tiga sifat, yaitu (1) sinergis, meningkatnya aktivitas biologis akibat pencampuran, (2) aditif, yang artinya aktivitas biologis hasil pencampuran sama dengan sebelumnya, dan (3) antagonis, aktivitas biologis akibat pencampuran lebih rendah dari komponen penyusunnya. Herbisida yang digunakan dalam percobaan ini adalah herbisida campuran yang mengandung bahan aktif IPA glifosat, imazetapir, dan karfentrazon etil.

Hebisida dengan kandungan bahan aktif glifosat merupakan herbisida pascatumbuh yang bersifat kontak dan nirselektif yang dapat digunakan untuk mengendalikan gulma daun lebar serta gulma rumput (Tomlin, 2011). Herbisida glifosat yang di serap oleh tanaman bekerja dengan cara menghambat kerja enzim EPSP synthetase, sehingga aktivitas reduksinitrat, fotorespirasi, dan metabolisme asam amino yang terikat oleh enzim tersebut terganggu. Kondisi ini mengkibatkan tanaman keracunan $\mathrm{NH}_{4}$ serta terganggunya fotorespirasi dan tidak terbentuknya asam amino, yang dapat mengakibatkan perusakan atau tidak membentuk dinding sel (Ribas etal., 2005).Imazetafiradalah herbisida nirselektif yang digunakan untuk mengendalikan berbagai gulma, termasuk rumput tahunan, abadi tahunan, tumbuhan berserat, spesies kayu, dan spesies air yang muncul. Herbisida ini mengendalikan pertumbuhan gulma dengan mencegah sintesis rantai cabang asam amino (Tuetal., 2001). Karfentrazon-etil adalah herbisida postemergence baru yang ditemukan untuk mengendalikan beberapa spesies berdaun lebar. Herbisida ini merupakan herbisida kontak yang mampu menimbulkan gejala kerusakan dalam beberapa jamsetelah aplikasi, dan kematian dapat terjadi dalam waktu 24 jam (Mack and Nissen, 2000).

Pencampuran herbisida bahan aktif glifosat, imazetapir, dan karfentrazon-etil, yang 
telah diketahui memiliki keunggulan masingmasing jika diterapkan secara tunggal, diharapkan efektivitasnya meningkat secara sinergistik sehingga memiliki spektrum pengendalian gulma yang lebih luas. Penelitian ini bertujuan untuk menguji sifataktivitas herbisida campuran berbahan aktif IPA glifosat, Imazetapir, dan Karfentrazon-etil terhadap beberapa jenis gulma sehingga dapat meningkatkan keefektifan herbisida dalam mengendalikan gulma secara berkelanjutan.

\section{Bahan dan Metode}

Percobaan ini dilaksanakan di rumah plastik di Laboratorium Kultur Terkendali Fakultas Pertanian Universitas Padjadjaran, Kecamatan Jatinangor, Kabupaten Sumedang, Jawa Barat. Percobaan dilakukan selama 3 bulan, mulai dari Oktober 2018 sampai dengan Januari 2019.

Bahan-bahan yang digunakan dalam penelitian ini terdiri dari propagul gulma dari kelompok gulma daun lebar (Ageratum conyzoides dan Borreria alata), gulma berdaun sempit (Ischaemum timorense dan Ottochloa nodosa), dan gulma teki (Cyperus rotundus), polibag, tanah, air, dan herbisida campuran IPA glyfosat $380 \mathrm{~g} / \mathrm{L}+$ imazetapir $40 \mathrm{~g} / \mathrm{L}+$ karfentrazon-etil $8 \mathrm{~g} / \mathrm{L}$, herbisida tunggal IPA glyfosat $380 \mathrm{~g} / \mathrm{L}$, imazetapir $40 \mathrm{~g} / \mathrm{L}$, dan karfentrazon-etil $8 \mathrm{~g} / \mathrm{L}$. Penelitian dilakukan dengan metode eksperimen dengan perlakuan seperti pada Tabel 1 .

Alat-alat yang digunakan dalam penelitian ini adalah: pot/ember plastik, knapsack sprayer semi otomatis, nozel T-jet, gelas ukur, gelas piala, pinset, oven untuk mengeringkan gulma, timbangan analitik mengukur bobot kering gulma, amplop untuk membungkus gulma, dan alat tulis.
Berdasarkan Ismawati et al. (2017), pengamatan dan analisa data dilakukan terhadap :

a. Bobot kering gulma yang dikonversi menjadi persen kerusakan.

$$
\% \mathrm{KP}=(1-\mathrm{Bsp} / \mathrm{Bsk}) \times 100 \%
$$

dimana \%KP adalah persen kerusakan perlakuan, Bsp adalah bobot kering bagian gulma yang masih segar karena perlakuan herbisida (g), dan Bsk adalah bobot kering bagian gulma yang masih segar pada kontrol (g).

b. Persen kerusakan dikonversi kedalam nilai probit untuk menentukan LD $_{50}$,kemudian dosis diubah kedalam bentuk logaritma dosis. Dari nilai probit $(Y)$ dan log dosis (X) dapat diperoleh persamaan regresi linear probit $\mathrm{Y}=\mathrm{aX}+\mathrm{b}$.

c. Menghitung nilai probit masing-masing herbisida

d. Menghitung LD50perlakuan masing-masing herbisida

e. Menghitung nilai $L_{50}$ perlakuan masingmasing herbisida dalam $\mathrm{LD}_{50}$ perlakuan campuran herbisida

f. Menghitung persentase kerusakan masingmasing herbisida

g. Menghitung persentase kerusakan campuran herbisida pada LD $_{50}$ perlakuan dan $\mathrm{LD}_{50}$ harapan

$$
\mathrm{P}(\mathrm{A}+\mathrm{B})=\mathrm{P}(\mathrm{A})+\mathrm{P}(\mathrm{B})-\mathrm{P}(\mathrm{A}) \times \mathrm{P}(\mathrm{B})
$$

dimana $\mathrm{P}(\mathrm{A}+\mathrm{B}+\mathrm{C})$ adalah persentase kerusakan campuran herbisida, $\mathrm{P}(\mathrm{A})$ dan $\mathrm{P}(\mathrm{B})$ adalah persentase kerusakan masingmasing herbisida secara tunggal.

h. Kriteria sifat campuran herbisida bersifat aktif campuran dapat diuji didasarkan pada nilai ko-toksisitas pada $\mathrm{LD}_{50 \%}=\mathrm{LD}_{50}$ harapan dibagi dengan $\mathrm{LD}_{50}$ hasil pengujian. Jika nilai ko-toksisitas $>1$ berati campuran herbisida tersebut sinergis, namun jika nilai $<1$ berarti campuran tersebut antagonis (Streibig, 2003).

Tabel 1. Perlakuan dosis herbisida.

\begin{tabular}{llllll}
\hline \multirow{2}{*}{ Perlakuan } & \multicolumn{5}{c}{ Dosis(L/ha) } \\
\cline { 2 - 6 } & $\mathrm{x}$ & $1 / 2 \mathrm{x}$ & $1 / 4 \mathrm{x}$ & $1 / 8 \mathrm{x}$ & $1 / 16 \mathrm{x}$ \\
\hline Herbisida campuran & 2 & 1 & 0,5 & 0,25 & 0,125 \\
IPA glyfosat 380 g/1 & 3 & 1,5 & 0,75 & 0,375 & 0,1875 \\
Imazetapir 40 g/1 & 3 & 1,5 & 0,75 & 0,375 & 0,1875 \\
Karfentrazon etil 7 g/1. & 3 & 1,5 & 0,75 & 0,375 & 0,1875 \\
Kontrol & 0 & 0 & 0 & 0 & 0 \\
\hline
\end{tabular}




\section{Hasil dan Pembahasan}

Fitotoksisitas. Gejalaawal pada daun dan batang gulma berdaun lebar (Ageratum conyzoides, dan Borreria alata), gulma berdaun sempit (Ischaemum timorensedan Ottochloa nodosa), dan golongan teki-teki (Cyperus rotundus), setelah disemprot herbisida campuran IPA glyfosat, imazetapir, dan karfentrazon-etil adalah kaku, daun berwarna kuning, dan ujung daun menjadi melipat, terkulai, atau layu. Selanjutnya gulma mati karena mengalami pembusukan pada batang bawah dan akar (5HSA) mulai dari dosis rendah. Herbisida IPA glyfosat menyebabkan pembusukan pada gulma Ageratum conyzoides, Borreria alata, Ischaemum timorense, dan Ottoclhoa nodosa dan Cyperus rotundus, mulai dari daun sampai akar gulma dan akhirnya mati. Gejala yang ditunjukkan akibat pemberian herbisida Imazetafir pada gulma daun lebar adalah daun mengeras dan selanjutnya menguning. Gejala yang ditimbulkan oleh herbisida karfentrazonetil terhadap gulma target hampir sama dengangejala yang ditimbulkan oleh herbisida IPA glifosat, tetapi gejalanya lebih ringan.

Persentase Kerusakan. Persentase kerusakan gulma diperoleh dari data bobot kering gulma kemudian nilai tersebut digunakan untuk perhitungan probit. Dosis herbisida yang semakin tinggi menyebabkan kerusakan gulma semakin meningkat. Keadaan ini dipengaruhi oleh jenis gulma, herbisida, dan dosis yang digunakan. Gambar 1 menjelaskan bahwa perlakuan aplikasi herbisida campuran IPA glifosat, imazetapir, dan karfentrazon-etil nyata menunjukkan nilai persen kerusakan yang lebih besar, dibandingkan dengan perlakuan herbisida tunggal imazetafir dan herbisida tunggal IPA glifosat. Nilai persen kerusakan sebesar $81,19 \%$ yang ditimbulkan pada perlakuan herbisida campuran pada dosis sesuai formulasi rekomendasi 2,00L/ha menunjukkan bahwa herbisida mampu mengendalikan lebih dari 50\% populasi gabungan gulma (Heong and Escalada, 1995).

Pengujian herbisida campuran dengan menggunakan enam jenis gulma lebih efektif dibandingkan jika menggunakan satu jenis gulma saja. Menurut Kristiawati (2003), pengujian tipe campuran herbisida lebih baik dilakukan terhadap minimal dua jenis gulma dari golongan yang berbeda.

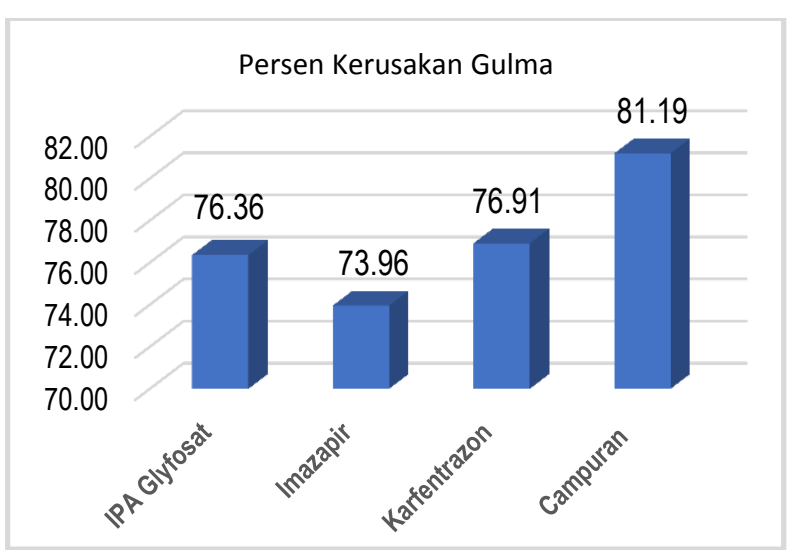

Gambar 1. Persentase kerusakan gulma uji.

Analisis Sifat Campuran Herbisida. Berdasarkan hasil analisis regresi, penggunaan herbisida campuran dan penggunaan herbisida tunggal terhadap gulma uji ditunjukkan padaTabel 3 di bawah ini.

Tabel 3. Nilai regresi herbisida.

\begin{tabular}{ccc}
\hline Herbisida & Persamaan Regresi & $\mathrm{R}^{2}$ \\
\hline Herbisida Campuran & $\mathrm{Y}=1,0303 \mathrm{x}+3,7546$ & 0,9742 \\
IPA glifosat 380 g/L & $\mathrm{Y}=1,1172 \mathrm{x}+3,1631$ & 0,9971 \\
Imazetafir 40 g/L & $\mathrm{Y}=1,4076 \mathrm{x}+3,2007$ & 0,9882 \\
Karfentrazon etil 8 g/L & $\mathrm{Y}=1,5782 \mathrm{x}+3,8001$ & 0,9973 \\
\hline
\end{tabular}

Berdasarkan nilai $\mathrm{R}^{2}$ yang terdapat pada Tabel 3, prediksi persentase kerusakan gulma gulma berdaun lebar (Ageratum conyzoides, dan Borreria alata), gulma berdaun sempit (Ischaemum timorense dan Ottochloa nodosa), dan golongan teki-teki (Cyperus rotundus) sebagai tumbuhan uji adalah akurat karena lebih dari 80\%. Nilai $\mathrm{R}^{2}$ yang tinggi antara 0,97-0,99 menunjukkan adanya hubungan antara X (dosis) dan Y (bobot kering gulma) yang sangat erat. Pada regresi linier yang diperoleh, semakin tinggi dosis herbisida yang diberikan sesuai dosis rekomendasi dapat meningkatkan persentase kerusakan gulma yang diuji dengan menurunkan bobot kering gulma (Kurniadie et al., 2019).

Herbisida campuran yang diteliti tersusun atas tiga komponen bahan aktif, yaitu IPA glifosat $380 \mathrm{~g} / \mathrm{L}$ dan imazetafir $40 \mathrm{~g} /$ Lserta Karfentrazon-etil $8 \mathrm{~g} / \mathrm{L}$. Ketiga herbisida tersebut berasal dari grup yang berbeda. Sehingga metode MSM merupakan pendekatan yang dapat digunakan untuk mengetahui tipe campuran herbisida yang berasal dari grup herbisida yang berbeda (Widayat et al., 2018; Kurniadie et al., 2019) Ketika nilai dosis 
perlakuan telah diketahui, maka selanjutnya perlu diketahui prediksi nilai dosis $\mathrm{LD}_{50}$ yang sebenarnya dari campuran herbisida tersebut yang dinyatakan dalam nilai $\mathrm{LD}_{50}$-harapan. Sifat campuran herbisida ditentukan dengan membandingkan nilai $\mathrm{LD}_{50}$-harapan dengan nilai $\mathrm{LD}_{50}$-perlakuan. Secara lebihrinci dapat dibuat dalam analisis aljabar pada Tabel 4.

Kerusakan gulma oleh IPA glifosat dan imazetafir dalam bentuk probit oleh kedua herbisida tersebut dapat dilihat pada Tabel 5 . Hasil perhitungan pada Tabel 5 digunakan untuk menghitung Persamaan probit tingkat kerusakan gulma oleh setiap komponen campuran pada Tabel 6. Analogi penghitungan kerusakan yang sama untuk herbisida imazetafir dan karfentrazon-etildilakukan pada Tabel 7 . Data Tabel 7 digunakan untuk menghitung Persamaan Probit tingkat kerusakan gulma oleh setiap komponen campuran pada Tabel 8.

Berdasarkan hasil perhitungan, $\mathrm{LD}_{50}$ percobaan lebih kecil dibandingkan $\mathrm{LD}_{50}$ harapan antara bahan aktif IPA glifosat dengan imazetafir, maupun imazetafir dengan bahan aktif karfentrazon etil. Nilai kotoksisitas lebih dari satu $(>1)$, menunjukkan bahwa campuran ketiga bahan aktif herbisida (IPA glifosat, imazetafir, dan karfentrazon-etil) menghasilkan sifat yang sinergis,sebab nilai kerusakan yang disebabkan oleh herbisida campuran lebih tinggi dibandingkan dengan kerusakan yang disebabkan oleh herbisida tunggal (Zimdahl, 2007). IPA glifosat, imazetafir, dan karfentrazon-etil adalah ketiga bahan aktif herbisida yang memiliki perbedaan golongan kimia dan perbedaan mode of action dalam mempengaruhi pertumbuhan gulma, tetapi ketiga bahan aktif herbisida yang digunakan sebagai bahan aktif campuran dapat saling bersinergi untuk menghambat kerja enzim atau proses fisiologis gulma.

Tabel 5. Kerusakan Gulma oleh IPA glifosat dan imazapir.

Oleh IPA glifosat $380 \mathrm{~g} / \mathrm{L} \quad$ 5,014055727 Probit Oleh imazetafir $40 \mathrm{~g} / \mathrm{L}$ 4,683466279 Probit

Tabel 4. Kerusakan gulma oleh herbisida tunggal dan campuran dan $\mathbf{L D}_{50}$.

\begin{tabular}{|c|c|c|c|}
\hline & Log Dosis & \multicolumn{2}{|c|}{ LD50 (g ai/ha) } \\
\hline Herbisida campuran & $X 1=-0,8373$ & Antilog X1 & 0,14544 \\
\hline IPA glifosat $380 \mathrm{~g} / \mathrm{L}$ & $X 2=-0,3106$ & Antilog X2 & 0,48912 \\
\hline Imazetafir $40 \mathrm{~g} / \mathrm{L}$ & $X 3=-0,4094$ & Antilog X3 & 0,38957 \\
\hline Karfentrazon-etil $8 \mathrm{~g} / \mathrm{L}$ & $X 4=-3,6994$ & Antilog X4 & 0,00020 \\
\hline
\end{tabular}

Tabel 6. Probabilitas kerusakan gulma akibat perlakuan campuran herbisida IPA glifosat dan imazafir.

\begin{tabular}{|c|c|c|c|}
\hline Persamaan Probit: & $\begin{aligned} \mathrm{P}(\mathrm{AB}) & = \\
= & \end{aligned}$ & $\begin{array}{l}\mathrm{PA}+\mathrm{PB}-\mathrm{PAPB} \\
21,50+37,50-8,11\end{array}$ & \\
\hline & & 50,89 & $\%$ \\
\hline LD50-c Percobaan = & & & 0,14544 \\
\hline LD50-c Harapan= & & & 0,5818 \\
\hline Ko-toksisitas $=$ & & & 4,0 \\
\hline
\end{tabular}

Tabel 7. Kerusakan Gulma oleh imazetafir dan karfentrazon-etil

Oleh imazetafir40 g/L $\quad 4,810504869 \quad$ Probit

Oleh karfentrazon-etil 8 g/L $\quad 5,464605051 \quad$ Probit

Tabel 8. Probabilitas kerusakan gulma akibat perlakuan campuran herbisida imazetafir dan karfentrazon-etil

\begin{tabular}{|c|c|c|c|}
\hline $\begin{array}{l}\text { Persamaan Probit : } \\
\mathrm{P}(\mathrm{AB})=\mathrm{PA}+\mathrm{PB}-\mathrm{PAPB}\end{array}$ & \multicolumn{3}{|c|}{$\begin{aligned} \mathrm{P}(\mathrm{AB}) & =\mathrm{PA}+\mathrm{PB}-\mathrm{PAPB} \\
& =27,00+32,00-8,64\end{aligned}$} \\
\hline LD50c harapan $=$ & 0,4363 & & (g ai/ha) \\
\hline LD50c percobaan $=$ & 0,14544 & & (g ai/ha) \\
\hline Ko-toksisitas $=$ & 2,99 & & \\
\hline
\end{tabular}




\section{Kesimpulan}

Persentase kerusakan yang disebabkan oleh herbisida campuran IPA glifosat,imazetafir, dan karfentrazon-etillebih tinggi daripada masingmasing herbisida secara tunggal. Sifat campuran herbisida IPA glifosat dengan imazetafir atau imazetafir dengan karfentrazon-etil adalah sinergis dengan memiliki nilai ko-toksisitaslebih dari satu $(>1)$.

\section{Daftar Pustaka}

Guntoro, D. dan T. Y. Fitri. 2013. Aktivitas Herbisida Campuran Bahan Aktif Cyhalofop-Butyl dan Penoxsulam terhadap Beberapa Jenis Gulma Padi Sawah. Buletin Agrohorti 1 (1) : 140-148

Heong, K. L., and M. M. Escalada. 1995. A comparative Analysis of Pest Management Practices of Rice Farmer in Asia. In: K. L. Heong, M. M. Escalada (eds). Pest Management of Rice Farmers in Asia. International Rice Research Institute. Los Banos. Philppines. p 227-245.

Ismawati, N. Sriyani, dan H. Pujisiswanto. 2017. Pengujian efektivitas herbisida berbahan aktif glifosat, mesotrion, s-metolaklor dan campuran ketiganya terhadap gulma teki. J. Agrotek Tropika, 5(3): 181 - 187.

Kurniadie, D., U. Umiyati, dan S. Shabirah. 2019. Pengaruh campuran herbisida berbahan aktif atrazin $500 \mathrm{~g} / \mathrm{L}$ dan mesotrion $50 \mathrm{~g} / \mathrm{L}$ terhadap gulma dominan pada tanaman jagung (Zea mays L.). J. Kultivasi, 18(2): 912 $-918$.
Mack,T. W., andS. J. Nissen.2000. Absorption and fate of carfentrazone-ethyl in Zea mays, Glycine max, and Abutilon theophrasti. Weed Science, 48(1), 15-19.

Ribas, A.F., A. K. Kobayashi, L. F. P. Pereira, and L. G. E. Vieira. 2005. Genetic transformation of Coffea canephora by particle bombardment. Biologia Plantarum, 49(4), pp.493-497

Sembodo, Drj. 2010.Gulma dan Pengelolaannya. Graha Ilmu. Yogyakarta.

Streibig, J. C. 2003. Assessment of herbicide effects.CRC Press. Boca Raton. Florida. USA. 22 - 31.

Tjitrosemito, S., dan A.H. Burhan. 1995. Campuran Herbisida (Suatu Tinjauan). Prosiding. Seminar Pengembangan Aplikasi Kombinasi Herbisida. 28 Agusutus 1995. Jakarta. pp.25-36.

Tomlin, C. D. S. 2011. The e-Pesticides Manual Version 3.0 (thirteenth edition). British Crop Protection Council

Tu, M., C. Hurd, dan J. M. Randall. 2001. Weed Control Methods Handbook.The Nature Conservancy.

Umiyati, U. 2005. Sinergisme campuran herbisida klomazon dan metribuzin terhadap gulma. Jurnal Agrijati. 1(1): 216219.

Weedscience. 2011. Herbicide Resistant Weed Summary Table. http:/ / www.weedscience. org. [Januari 2019].

Widayat, D., U. Umiyati, Y. Sumekar, dan D. Riswandi. 2018. Sifat campuran herbisida berbahan atrazin $500 \mathrm{~g} / \mathrm{L}+$ mesutrion 50 $\mathrm{g} / \mathrm{L}$ terhadap beberapa jenis gulma. J. Kultivasi, 17(2): 670 - 675.

Zimdahl, R.L. 2007. Fundamentals of weed science. 3rd ed. Academic Press, Inc., San Diego, CA 